\title{
Healing in Primary Care: A Vision Shared by Patients, Physicians, Nurses, and Clinical Staff
}

\author{
Clarissa Hsu, PbD ${ }^{1}$ \\ William R. Pbillips, MD, MPH \\ Karen J. Sherman, $P b D, M P H^{3}$ \\ Rene Hawkes, $B^{3}$ \\ Daniel C. Cherkin, PbD \\ 'Group Health Center for Community \\ Health and Evaluation, Seattle, Washington \\ ${ }^{2}$ Department of Family Medicine, Univer- \\ sity of Washington, Seattle \\ ${ }^{3}$ Group Health Center for Health Studies, \\ Seattle, Washington
}

Conflicts of interest: None reported.

\section{CORRESPONDING AUTHOR}

Clarissa $\mathrm{Hsu}, \mathrm{PhD}$

Center for Community Health and

Evaluation

1730 Minor Ave, Suite 1600

Seattle, WA 98101

hsu.c@ghc.org

\begin{abstract}
PURPOSE We wanted to understand the views of patients and clinicians on the central concept of healing and to identify major facilitators of and barriers to promoting healing in primary care.

METHODS We undertook a qualitative analysis of focus group discussions. Participants were drawn from primary care clinics of a large, integrated, health care system in Washington State in 2005. Nine focus groups included 84 participants: 28 patients, 23 primary care physicians (19 family physicians), 20 registered nurses, 11 licensed practical nurses, and 2 medical assistants. Randomly sampled established patients were aged from 21 to 65 years; $71 \%$ were female.

RESULTS We found remarkable concordance across focus groups and among types of participants in the definition of healing: Healing is a dynamic process of recovering from a trauma or illness by working toward realistic goals, restoring function, and regaining a personal sense of balance and peace. Healing is a multidimensional process with physical, emotional, and spiritual dimensions. The key themes are as follows: (1) healing is multidimensional and holistic; (2) healing is a process, a journey; (3) the goal of healing is recovery or restoration; (4) healing requires the person to reach a place of personal balance and acceptance; and (5) relationships are essential to healing. Factors that facilitate healing help build relationships, improve communication, and share responsibility between the patient and clinician. Major barriers are logistical factors that limit high-quality time with healing professionals.
\end{abstract}

CONCLUSIONS Patients and health care team members share a vision of healing and agree on ways to enhance the process in primary care.

Ann Fam Med 2008:6;307-314. DOI: 10.1370/afm.838.

\section{INTRODUCTION}

$\mathrm{H}$ ealing is a central concern of medicine, yet the role it plays in our modern health care system is poorly defined..$^{1-3}$ Biomedical research on healing is usually limited to the level of tissue repair. Broader study of healing appears in literature from other fields. Nursing discusses healing with a focus on the process of caring and the nurse as healer. ${ }^{4-6}$ Anthropological research on healing tends to focus on documenting nonbiomedical practices and eliciting deep symbolic and structural meanings from healing practices. ${ }^{7.8}$ Complementary and alternative medicine often examines systems of healing outside the scientific biomedical model. ${ }^{9-11}$ Healing plays a central role in psychology ${ }^{12}$; however, with the exception of a few Jungian psychotherapists, the meaning of healing goes unexplored. ${ }^{13}$ Other researchers have explored the meaning of healing in patients with chronic illness ${ }^{14,15}$ disability, ${ }^{16}$ pain, ${ }^{17,18}$ and at the end of life. ${ }^{19,20}$

There has been little empirical research on healing in modern health care, and we have little evidence on how physicians and other members 
of primary care clinical teams see their roles in healing. ${ }^{21}$ No published research has systematically asked patients in primary care what they define as healing or how it might be improved.

Egnew $^{22}$ sought the definition of healing from selected medical experts and expressed concern about physicians' lack of capacity for the empathy, communication, and relationships essential to healing. Leaders in medical education are calling for renewed attention to the importance of healing in patient care. ${ }^{2,23}$ Some "believe an emphasis on healing is key to the future of medical management of chronic illness and the establishment of sustainable approaches to health care."24

Meaningful discussion about healing requires an understanding of what healing means to the key participants in the healing process: patients, physicians, nurses, and other members of the primary care team. ${ }^{25-27}$ We used qualitative research methods to explore what they believe are definitions, fundamental dimensions, barriers, and opportunities for improvement of healing.

\section{METHODS}

This research was part of a larger effort to improve patient outcomes in primary care by enhancing the healing experience for patients, clinicians, and the primary health care team. We conducted the study in a large, integrated, consumer-governed, health care system in Washington State in 2005. We conducted 19 individual interviews to develop a discussion guide for the focus groups we report here. The Institutional Review Board of Group Health Cooperative approved all components of this study.

Our interdisciplinary team began with several assumptions based on discussions with a broad variety of professionals interested in enhancing healing environments. We expected healing would be a difficult concept to define and discuss, particularly across patient and professional groups. We also expected that many patients would consider healing to be the domain of alternative and/or spiritual practices, rather than an integral part of conventional medical practice.

We recruited both patients and clinicians for focus groups from the Seattle and Tacoma, Wash, metropolitan areas, using a multistage process that is detailed in the Supplemental Appendix 1 (available online-only at http://www.annfammed.org/cgi/ content/full/6/4/307/DC1). We started with a random sample of established patients, stratified by sex, age, and medical condition. Letters were mailed to patients inviting them to participate in a study "to better understand how a patient's personal experiences with their health care team may affect his or her ability to heal," and to participate "in a discussion group...to share their thoughts about how the patient-provider relationship can help or hinder healing." We recruited physicians and clinical team members through email invitations to all such personnel in the primary care clinics in the study regions. For all those who responded, we explained the study procedures and obtained informed consent by telephone. We paid cash incentives to focus group participants (patients $\$ 75$, nursing staff $\$ 100$, physicians $\$ 150$ ).

We conducted a series of 9 focus groups during July and August 2005 (Table 1). Seven groups were homogeneous: 2 groups each of only patients, primary care physicians, and registered nurses (RNs), and 1 group comprising licensed practical nurses (LPNs) and medical assistants (MAs). Considering the debate about homogenous vs heterogeneous focus groups, we conducted 2 additional groups that included a mix of participants of all 4 types. The size and format of the focus groups followed recommendations in the literature. ${ }^{28-31}$ We contracted with 2 independent, professional facilitators from a local marketing and consulting firm to lead the focus groups. They used a discussion guide designed to elicit (1) concepts and definitions of

\begin{tabular}{|c|c|c|c|c|}
\hline Group & Participants & Number & Female & Male \\
\hline 1 & Patients & 12 & 7 & 5 \\
\hline 2 & Patients & 9 & 5 & 4 \\
\hline 3 & Physicians & 9 & 5 & 4 \\
\hline 4 & Physicians & 10 & 6 & 4 \\
\hline 5 & RNs & 11 & 11 & 0 \\
\hline 6 & RNs S & 6 & 6 & 0 \\
\hline 7 & LPNs; MAs & $\begin{array}{l}10 \\
9 \text { LPNs } \\
1 \mathrm{MA}\end{array}$ & 10 & 0 \\
\hline 8 & Mixed group & $\begin{array}{l}10 \\
4 \text { Patients } \\
2 \text { Physicians } \\
2 \text { RNs } \\
2 \text { LPNs }\end{array}$ & 6 & 4 \\
\hline 9 & Mixed group & $\begin{array}{l}7 \\
3 \text { Patients } \\
2 \text { Physicians } \\
1 \text { RNs } \\
1 \mathrm{MA}\end{array}$ & 4 & 3 \\
\hline $\begin{array}{l}\text { Totals, } \\
\text { No. (\%) }\end{array}$ & & $\begin{array}{l}85 \text { Total } \\
28 \text { Patients } \\
23 \text { Physicians } \\
20 \text { RNs } \\
11 \text { LPNs } \\
2 \text { MAs }\end{array}$ & $60(71)$ & $24(29)$ \\
\hline
\end{tabular}


healing, (2) facilitators to the healing process, and (3) potential barriers to healing (Supplemental Appendix

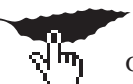
2, available online-only at http://www.annfammed org/cgi/content/full/6/4/307/DC1). In each group, after all participants offered their own thoughts on healing, the group constructed a consensus definition of healing. We made audio recordings of all discussions that were transcribed verbatim, either from the audiotapes (3) or in real time by a stenographer present in the room (6). Members of the research team were present at all the focus groups.

We examined the content of the focus group discussions at biweekly meetings of the research team. Inclusion of clinicians and clinic trainers in these discussions helped validate interpretation of comments and themes. We judged that we reached saturation in eliciting new salient comments on healing well before we completed the groups we planned.

The analysis team identified the key themes, using an immersion/crystallization approach. ${ }^{32}$ Four team members (C.H., K.S., R.H., W.P.) read all transcripts in detail. Three team members (C.H., K.S., R.H.) independently coded 2 transcripts and generated a list of codes for the major themes and concepts, using Atlas. ti (ATLAS.ti Scientific Software Development GmbH, Berlin, Germany). They discussed all codes and developed consensus regarding the content and definitions of a coding scheme. All 3 coders then coded 2 complete transcripts, again reconciled the codes, and agreed on a final code list. Agreement among coders during this first phase was approximately $70 \%$. Finally, at least 2 team members coded each transcript, compared results, and resolved any differences though discussion. Agreement in the final phase was approximately $90 \%$. This process allowed the analysis team to closely reflect on the data, identify emerging patterns, and learn from each other's perspectives. The process followed the constant comparative method of grounded theory, comparing and refining codes throughout the data analysis process. ${ }^{33}$ Once all transcripts were coded and compared, 2 members of the team (C.H., W.P.) focused on references to healing. They reread and further analyzed the data under relevant codes to identify the findings described in this article.

The analysis team represented a variety of backgrounds: a medical anthropologist with special interest in women's health care and community health (C.H.); a family physician researcher with special interest in patient-doctor communication and preventive services (W.P.); an epidemiologist experienced in conducting clinical trials of complementary and alternative medicine (K.S.), and a public health research manager with a background in psychology (R.H.).

We initially expected to consider the patient discussions as 1 data set and the clinician discussions as 1 or more separate data sets. Early in the analysis, however, we found that all groups shared remarkably similar views on healing. We therefore combined the data from all groups.

\section{RESULTS}

We conducted 9 focus group discussions with 84 participants. Response rates are summarized in Supplemental Appendix 1. The composition of the groups is displayed in Table 1. Twenty-eight patients ranged in age from 22 to 62 years, with $71 \%$ female and $29 \%$ male. The 23 physicians ( 21 family physicians, 1 general internist, and 1 general pediatrician) worked in 13 different primary care clinics, in both urban and suburban communities. Focus groups included other key members of the clinical teams: RNs (20), LPNs (11), and MAs (2), drawn from across 13 clinics. We refer to them all as clinicians.

\section{Definition of Healing}

The central finding across the focus groups was a surprising level of concordance on the definition of healing. Each group crafted a consensus definition. The commonality is apparent in Table 2.

From these group definitions, expanded by the range and depth of discussion and interview data, we
Table 2. Definition of Healing by Focus Groups

\begin{tabular}{|c|c|c|}
\hline Group & Participants & Definition of Healing \\
\hline 1 & Patients & The process of regaining wellness \\
\hline 2 & Patients & Restoring a sense of well-being \\
\hline 3 & Physicians & $\begin{array}{l}\text { The process of helping a person restore mental, spiritual, and } \\
\text { physical health by removing barriers for optimum functioning }\end{array}$ \\
\hline 4 & Physicians & Assisting a person to reach his/her full potential and full function \\
\hline 5 & RNs & $\begin{array}{l}\text { A pathway between personal sense of illness and wellness, inte- } \\
\text { grating the spiritual, mental, physical, and relational }\end{array}$ \\
\hline 6 & RNs & The process of helping an individual achieve a state of wellness \\
\hline 7 & LPNs - MAs & $\begin{array}{l}\text { Treating the whole person spiritually, emotionally and physically, } \\
\text { not just their ailment (improvement in condition) }\end{array}$ \\
\hline 8 & Mixed group & $\begin{array}{l}\text { The process of moving toward balance and well-being that implies } \\
\text { making changes and the blending of the physical, mental, and } \\
\text { spiritual }\end{array}$ \\
\hline 9 & Mixed group & $\begin{array}{l}\text { The restoration of health with caring, acceptance, and } \\
\text { understanding }\end{array}$ \\
\hline
\end{tabular}




\section{Table 3. Themes on Healing and Example Quotations From Patient and Clinician Groups}

\begin{tabular}{|c|c|}
\hline Theme & Speaker \\
\hline \multicolumn{2}{|l|}{ 1. Healing is multidimensional and holistic } \\
\hline Healing is more mental than physical. It's holistic, spiritual, emotional, and physiologic & Patient (group 2) \\
\hline $\begin{array}{l}\text { I think healing for me is a very complex kind of concept.... There is a mental part, there is a physical part, there is } \\
\text { a spiritual part }\end{array}$ & Physician (group 3) \\
\hline $\begin{array}{l}\text { [Wholeness] I think that's a wonderful word for it. I don't believe it's lack of illness, I believe it goes further than } \\
\text { that...to include peace of mind. Peace: body, mind, and spirit }\end{array}$ & RN (group 5) \\
\hline It's not an organ system. It's the entire person. The mind, body, spirit, relationships, community, the whole person & LPN/MA (group 7) \\
\hline \multicolumn{2}{|l|}{ 2. Healing is a process, a journey } \\
\hline [Healing is]...going through a process of emotions to get over something extremely traumatic that happened & Patient (group 1) \\
\hline Maybe you should call it a path of restoring, so that maybe you don't get to the end point & Physician (group 3) \\
\hline $\begin{array}{l}\text {...sometimes there is going to be two steps forward and one step back, but it's the journey and skills that they } \\
\text { learn along the way, that seems to help the people move and get unstuck and make some steps forward. I think } \\
\text { patients need to realize that }\end{array}$ & RN (group 6) \\
\hline $\begin{array}{l}\text { As a doctor, if I can... recognize that healing is this process.... You may not be able to solve the problem that } \\
\text { particular day.... That it might take time, that we're going to have a follow-up. I'm really listening. We only got } \\
\text { these } 3 \text { things discussed, but I know there's many.... So, you are establishing a framework that's open ended }\end{array}$ & $\begin{array}{l}\text { Physician in mixed } \\
\text { group (group 8) }\end{array}$ \\
\hline \multicolumn{2}{|l|}{ 3. The goal of healing is recovery or restoration } \\
\hline It's a restorative process. Regenerative. Restoring something that was lost or the sense of well-being & Patient (group 2) \\
\hline $\begin{array}{l}\text { [Healing is] the process of restoring a person's mental, spiritual, and physical health, which is their suffering part, } \\
\text { and removing barriers to the level possible, and then to optimum }\end{array}$ & Physician (group 3) \\
\hline \multicolumn{2}{|l|}{ 4. Healing requires the person to reach a place of personal balance and acceptance } \\
\hline [Healing is] being OK with what you are right now. Acceptance. Living in the day & Patient (group 2) \\
\hline $\begin{array}{l}\text { Acceptance and understanding... [I]t's trying to work toward or move toward having the person be as happy and } \\
\text { as functional as they can possibly be, given their problems. Balance when I have sought health care }\end{array}$ & Physician (group 3) \\
\hline $\begin{array}{l}\text {...from my own personal patient experience, I have felt healed. I have felt that something that was amiss or out of } \\
\text { balance was brought back in }\end{array}$ & $\begin{array}{l}\text { Individual from mixed } \\
\text { group (group 8) }\end{array}$ \\
\hline Healing is living successfully with whatever challenges you have & $\begin{array}{l}\text { Individual in mixed } \\
\text { group (group } 8 \text { ) }\end{array}$ \\
\hline \multicolumn{2}{|l|}{ 5. Relationships are essential to healing } \\
\hline $\begin{array}{l}\text { Healing is the interpersonal relationships at my clinic and the nurses that took care of me when I was there. It has } \\
\text { less to do with the pain and more to do with personal attention }\end{array}$ & Patient (group 2) \\
\hline It means that it's just like "Cheers"; people want to go where people know your name & Physician (group 3) \\
\hline $\begin{array}{l}\text { I feel that good healing process is when the patient comes familiar with that nurse. Because that trust thing, and } \\
\text { plus that they expect we have become like family. I know my patients }\end{array}$ & LPN/MA (group 7) \\
\hline
\end{tabular}

synthesized this definition: Healing is a dynamic process of recovering from a trauma or illness by working toward realistic goals, restoring function, and regaining a personal sense of balance and peace. Healing is a multidimensional process that includes physical, emotional, and spiritual dimensions.

The key components of this shared definition were (1) healing is multidimensional and holistic ${ }_{i}$ (2) healing is a process, a journey; (2) the goal of healing is recovery or restoration ${ }_{i}(4)$ healing requires the person to reach a point of personal balance and acceptance ${ }_{i}$ (5) relationships are essential to healing. For each theme, example verbatim quotations are presented in Table 3, representing the variety of types of participants.

\section{Healing Is Multidimensional and Holistic}

Participants in all focus groups agreed that healing goes beyond addressing physical problems, to include the spiritual, emotional, and mental dimensions. Heal- ing requires understanding the patient as a whole person, not just addressing a discrete physical problem. This broad approach was often described as "holistic."

\section{Healing Is a Process, a Journey}

The common metaphor that emerged was healing as a journey. It starts after a person's sense of health or state of balance is disrupted, usually through some illness or trauma. Healing is the journey back toward the original level of function or balance. Focus group participants described the journey as an evolving process that may require changes in direction or final destination. Doctors and nurses act - as described by both patients and clinicians - as guides or helpers along the way. Many other helpers play important roles, notably family members, loved ones, spiritual guides, therapists, and friends. Physician participants acknowledged that a lot of healing occurs without their intervention. They usually function, not as the agents, but as facilitators 
of healing, connecting the patient with information or resources. Physician participants also talked about serving as witnesses to suffering and healing.

\section{The Goal of Healing Is Recovery or Restoration} The task of healing is to recover something lost, to restore the person to his or her former state of health or balance. In many cases, full recovery is possible, such as recovery from an infection or minor injury. When full recovery is not attainable, the goal is to restore the person as near as possible to his or her original state. "Health" was considered a person's level of function, rather than as an objective assessment of physical indicators. For example, it is not whether the bones in an injured hand mend properly, but whether the person is able to paint again. Few participants mentioned prevention, longevity, or high-level wellness as goal of healing. Changing harmful behaviors might aid in healing for some, but risk reduction was not considered a primary goal of healing.

\section{Healing Requires Reaching Personal Balance and Acceptance}

A key marker of healing is a sense of balance and acceptance. When full recovery is not possible, the goal of healing becomes reaching a state of balance or harmony with the level of function that is realistic for that person in that circumstance. Healing may also be attained by reaching understanding and acceptance of one's limitations. In the case of terminal illness or permanent disability, the goal of healing is acceptance. Balance also can refer to a dynamic state of equilibrium, stability, and peace.

\section{Relationships Are Essential to Healing}

Healing is a personal and an interpersonal process. Though it is a personal journey, it is not taken alone There was a strong emphasis across groups on the healing powers of communication, information, support, empathy, and compassion. Participants talked at length about the importance of relationships, especially relationships with primary care clinicians. The patient-doctor relationship is central, but relationships with other members of the care team (both clinical and clerical workers) also influence healing. Participants of all types emphasized the importance to healing of social support and relationships outside the health care system.

\section{Facilitators}

Groups identified the major factors that can facilitate healing, both generally and specifically in the context of medical care. Participants stressed that relationships are central to almost all facilitators and barriers. Facilitators were clustered into the themes outlined in Table 4 .

\section{Table 4. Themes on Facilitators and Barriers to Healing

\begin{tabular}{|c|c|c|}
\hline Theme & Facilitator & Barrier \\
\hline \multirow[t]{3}{*}{ Caring and connection } & Ability to make the patient feel heard and cared for & Lack of respect for patients \\
\hline & Communicating warmth & Distractions \\
\hline & Responsiveness to patient needs & Poor listening \\
\hline \multirow[t]{3}{*}{ Knowing the patient } & \multirow{2}{*}{$\begin{array}{l}\text { Clinicians having an in-depth knowledge of their patient's } \\
\text { history }\end{array}$} & Poor medical records \\
\hline & & Poor interpersonal communication skills \\
\hline & $\begin{array}{l}\text { Clinician's ability to intuitively assess the patient's desired } \\
\text { level of personal connection, information, and involvement } \\
\text { in care planning }\end{array}$ & \\
\hline \multirow[t]{4}{*}{ Continuity of care } & Relationship over time with one clinician or a team & \multirow{2}{*}{$\begin{array}{l}\text { Lack of communication systems among } \\
\text { clinicians }\end{array}$} \\
\hline & Contributes to "knowing the patient" & \\
\hline & & Inattention to the medical record \\
\hline & & Clinician turnover \\
\hline \multirow[t]{3}{*}{ Time } & "Time to heal" & \multirow[t]{3}{*}{ Time pressures } \\
\hline & Quality time during appointments to get needs met & \\
\hline & $\begin{array}{l}\text { Seeing one clinician over a period of months or years } \\
\text { (continuity of care) }\end{array}$ & \\
\hline \multirow[t]{2}{*}{ Social support } & \multirow{2}{*}{$\begin{array}{l}\text { Having friends, family and extended communities that } \\
\text { are supportive }\end{array}$} & Isolation \\
\hline & & Lack of social support \\
\hline \multirow[t]{5}{*}{ Office function } & \multirow{5}{*}{$\begin{array}{l}\text { Ease and pleasantness of arranging, receiving, and } \\
\text { providing care }\end{array}$} & Poor front desk experience \\
\hline & & Scheduling difficulties \\
\hline & & Staff unhappiness \\
\hline & & Lack of resources \\
\hline & & Poorly designed roles \\
\hline \multirow[t]{3}{*}{ Patient behavior } & \multirow[t]{3}{*}{ Patient's attitudes toward health and motivation for healing } & Unrealistic expectations on part of patients \\
\hline & & Difficulty of behavior change. \\
\hline & & Unhealthy behaviors (smoking, drinking, etc) \\
\hline
\end{tabular}


A key facilitator is a feeling of warmth, caring, and connection imparted by the clinicians and staff in the clinic setting. Participants repeatedly spoke about the need for clinicians to have in-depth knowledge of the patient and communication skills that foster positive interactions with the patient. Several processes are important for "knowing the patient": listening, good medical records, seeing the same clinicians over time, and ensuring continuity of information when transferring care.

Patients and clinicians alike frequently emphasized the importance of time. They believed that healing requires time, and time with the clinician is essential to the process of care. Patients believed it was the quality — not necessarily the quantity-of time that really mattered. Clinicians often expressed concern about the lack of time for meaningful interactions with patients

Physicians and other clinical team members recognized the importance of their own state of health. Several explained that their own experience of healing facilitated their effectiveness as caring professionals. Enhancing clinicians' ability to function in teams also can improve their effectiveness as healers and the health of their working environment. Several patients spoke of the need to reduce the stress suffered by clinicians to improve their ability to be healers.

\section{Barriers}

The major barriers to healing identified by clinicians and patients are simply the absence of the positive facilitating factors. Logistical factors most often pose barriers to healing, including the organization, delivery, and environment of medical care. All focus groups that included clinicians emphasized the importance of the patient's experience at the front desk. They observed that a negative encounter there sets the patient up to have a negative overall experience in the clinic.

Participants of all types also acknowledged that patients brought their own set of facilitators and barriers to the healing process. Patient participants emphasized, and clinicians agreed, that the patient bears the central responsibility for healing.

\section{DISCUSSION}

This study provides empirical data on the meaning of healing in primary care from the perspective of patients and clinicians, one of only a few such studies. ${ }^{22,34}$ We found a remarkable level of concurrence on the concept of healing among patients, physicians, nurses, and clinical assistants.

The definition of healing that emerged from patients and clinicians was generally consistent with definitions in the literature. ${ }^{22,27,35}$ We observed key themes emphasized by many others: wholeness, ${ }^{36,37}$ recovery, balance, communication, ${ }^{38}$ and relationships. ${ }^{39}$ These areas of agreement suggest a broad consensus on what healing is and how it is achieved. ${ }^{40}$

Consistent with recent work on the ways a person constructs and uses stories to articulate personal experience and meaning in clinical practice (also referred to as narrative), ${ }^{41-43}$ the stories our participants shared represent an archetypal narrative of healing as a personal journey. The starting point of the journey depends upon who the patient is and what trauma, illness, or other loss he or she has experienced. The destination depends upon the patient's personal goals and whether they are realistic. Doctors and nurses bring special knowledge and skills that are sometimes important in guiding or advancing the journey. The fundamental work of the healer, however, is to listen, hear, understand, and help the patient progress along the road toward recovery of wholeness and function. This help requires communication and the building of trusting relationships. Both patients and clinicians feel that the current burdens of workload, stress, and time pressure limit opportunities for healing.

The healing journeys described by our participants are similar to the type that Frank classifies as restitution narratives, ${ }^{41}$ except that technology seldom plays a prominent role in these narratives from primary care. Although most medical literature is devoted to the scientific and technical aspects of diagnosis and treatment, we did not find this emphasis when patients and clinicians talked of healing.

Many authors emphasize suffering and its relief in healing. ${ }^{3,44-46}$ Our participants focused less on the relief of suffering and more on the restoration of function. Some authors advocate careful attention to the design of the physical environment of the healing encounter, ${ }^{47.49}$ but the patients and clinicians in our study rarely mentioned the clinic space. Counter to our expectations, patients only occasionally expressed interest in complementary and alternative medicine (CAM) in connection with healing.

Spirituality is central to healing in much of the literature. ${ }^{50,51}$ It was important for our participants for its contribution to the wholeness of mind, body, and spirit. Participants believed faith was important in healing and that faith communities could provide important social support. Few participants, however, talked of faith healing, prayer, or divine intervention. In fact, there was little talk of being healed by any intervention. Throughout the discussions, the patient was the subject—not the object—of the healing process.

We designed this study to inform a new program to optimize healing in primary care. Limitations include a selective sample, biases generated by the context of the 
study, and limitations of responses that were due to the nature of the questions asked. Our study participants were drawn from patients in one large health care system with long traditions of patient advocacy, community involvement, emphasis on prevention, and clinical research. All patient participants had established relationships with primary care clinicians, mostly family physicians. In addition, our population is more educated, higher percentage white, and less religious than in many regions. The invitation letter stated our interest in healing and health care and might have attracted biased participants. Although our findings may not be generalizable to all people or settings, we feel that these voices likely represent many patients and professionals in primary care in the United States.

Conducting our study in a medical environment with patients in established relationships with medical doctors may have introduced bias against other models of care. Our community, however, has high rates of CAM use, ${ }^{52}$ including among patients who regularly see medical doctors. In addition, this system provides benefits for CAM treatments, as mandated in Washington State.

This study adds to current scholarship on healing by asking patients and clinicians what they think. This exploratory work found a surprising level of agreement among patients and clinicians in primary care settings. The patients and clinicians in our groups agree that medical care, though important, is only one contributor to healing. Likewise, healing is only one element of what goes on in modern medical care. Other expectations include symptom relief, prevention, control of chronic disease, and a range of administrative responsibilities. ${ }^{53}$ The participants we listened to made it clear, however, that healing is what brings patients and clinicians together. They also agreed that they need more unhurried time together to make it work. Further work is needed to explore agreement and differences across other medical specialties, professional groups, geographic regions, racial and ethnic groups, and health care systems. ${ }^{54}$ Finding better ways to heal might help us address some of the chronic problems facing health care today. ${ }^{55-57}$ Our team is using these findings to help guide changes in our primary care system, to increase clinician mindfulness, reduce stress, improve doctor-patient communication, and enhance clinic team function. ${ }^{58}$

This research raises fundamental questions about the goals of the US health care system and the place of primary care. Patients and clinicians in our study believed that healing is possible in our current system, but that much must be changed to foster healing relationships. Do we want a health care system focused on healing? What attitudes, priorities, and resources would we need to change? What expectations stand in the way? If we designed a system to heal, what would it look like?

To read or post commentaries in response to this article, see it online at http://www.annfammed.org/cgi/content/full/6/4/307.

Key words: Healing; health; patient care; delivery of health care; physician patient relationship

Submitted July 18, 2007; submitted revised December 29, 2007; accepted January 4, 2008.

Presented in part at the Annual meeting of the North American Primary Care Research Group, Vancouver, BC, Canada, October 20-23, 2007.

Funding support: This work was supported by grants from the Samueli Institute, Alexandria, Virginia, and Group Health Cooperative, Seattle, Washington.

Acknowledgments: The authors gratefully acknowledge the contributions of other members of the Optimizing Healing in Primary Care Project team: Larry B. Mauksch, MEd; Julia Smith, MD; Christel Kratohvil; Erika Holden; Barbara Findlay, RN; and Cheryl Wiese, MA.

\section{References}

1. Brody H. The Healer's Power. New Haven, CT: Yale University Press; 1992.

2. Lown B. The Lost Art of Healing. Boston, MA: Houghton Mifflin; 1996.

3. Cassell E. The Nature of Suffering and the Goals of Medicine. New York, NY: Oxford University Press; 1991.

4. Swanson KM. Nursing as informed caring for the well-being of others. Image J Nurs Sch. 1993;25(4):352-357.

5. Kritek PB, ed. Reflections on Healing: A Central Concept in Nursing. New York, NY: National League for Nursing; 1997.

6. Swanson K. What is known about caring in nursing science: a literary meta-analysis. In: Hinshaw AS, Feethan S, Shaver J, eds. Handbook of Clinical Nursing Research. Thousand Oaks, CA: Sage; 1999:31-60.

7. Kleinman AM. Some issues for a comparative study of medical healing. Int J Soc Psychiatry. 1973;19(3):159-163.

8. Csordas TJ, Kleinman AM. The therapeutic process. In: Johnson TM, Sargent CF, eds. Medical Anthropology: Contemporary Theory and Method. New York, NY: Praeger Publishers; 1990.

9. Samueli Institute. Towards Optimal Healing Environments in Health Care. In: 2nd American Samueli Symposium, Towards Optimal Healing Environments in Health Care. 2004 January 23-26; Newport Beach, CA: Samueli Institute; 2004.

10. Kaptchuk TJ, Eisenberg DM. Varieties of healing. 2: a taxonomy of unconventional healing practices. Ann Intern Med. 2001;135(3):196-204.

11. Barrett B, Marchand L, Scheder J, et al. What complementary and alternative medicine practitioners say about health and health care. Ann Fam Med. 2004;2(3):253-259.

12. Jackson SW. Care of the Psyche: A History of Psychological Healing. New Haven, CT: Yale University Press; 1999.

13. Hillman J. Healing Fiction. Barrytown, NY: Station Hill Press; 1983.

14. Kligler B. The role of the optimal healing environment in the care of patients with diabetes mellitus type II. J Altern Complement Med. 2004;10(Suppl 1):S223-S229. 
15. Marshall DA, Walizer E, Vernalis MN. Optimal healing environments for chronic cardiovascular disease. J Altern Complement Med. 2004;10(Suppl 1):S147-S155.

16. Geller G, Warren LR. Toward an optimal healing environment in pediatric rehabilitation. J Altern Complement Med. 2004;10(Suppl 1): S179-S192.

17. Cherkin D, Sherman KJ. Conceptualization and evaluation of an optimal healing environment for chronic low-back pain in primary care. J Altern Complement Med. 2004;10(Suppl 1):S171-S178.

18. Waters D, Sierpina VS. Goal-directed health care and the chronic pain patient: a new vision of the healing encounter. Pain Physician. 2006;9(4):353-360

19. Farber SJ, Egnew TR, Herman-Bertsch JL. Defining effective clinician roles in end-of-life care. J Fam Pract. 2002;51(2):153-158.

20. Silver S. Optimal healing environments in end-of-life care and beyond. J Altern Complement Med. 2004;10(Suppl 1):S201-S209.

21. Klimenko $E$, Julliard $K$, Shu-Hua L, Song H. Models of health: A survey of practitioners. Complement Ther Clin Pract. 2006;12(4):258-267.

22. Egnew TR. The meaning of healing: transcending suffering. Ann Fam Med. 2005;3(3):255-262

23. Novack DH, Epstein RM, Paulsen RH. Toward creating physician-healers: fostering medical students' self-awareness, personal growth, and well-being. Acad Med. 1999;74(5):516-520.

24. Miller WL, Crabtree BF. Healing landscapes: patients, relationships, and creating optimal healing places. J Altern Complement Med. 2005;11(Suppl 1):S41-S49.

25. Gunderman RB. Rethinking our basic concepts of health and disease. Acad Med. 1995;70(8):676-683.

26. Jonas WB, Chez RA. The role and importance of definitions and standards in healing research. Altern Ther Health Med. 2003;9(3) (Suppl):A5-A9.

27. Dossey L. Samueli conference on definitions and standards in healing research: working definitions and terms. Altern Ther Health Med. 2003;9(3)(Suppl):A10-A12.

28. Edmunds H. The Focus Group Research Handbook. Lincolnwood, IL: NTC Business Books; 1999.

29. Krueger RA, Casey MA. Focus Groups: A Practical Guide for Applied Research. 3rd ed. Thousand Oaks, CA: SAGE Publications; 2000.

30. Morgan DL. Focus Groups as Qualitative Research. 2nd ed. Thousand Oaks, CA: SAGE Sage Publications; 1997.

31. Stewart DW, Shamdasani PN, Rook DW. Focus Groups: Theory and Practice. 2nd ed. Thousand Oaks, CA: SAGE Publications; 2007.

32. Borkan J. Immersion/crystallization. In: Crabtree BF, Miller WL, eds. Doing Qualitative Research. 2nd ed. Thousand Oaks, CA: SAGE Publications; 1999:179-194

33. Corbin J, Strauss A. Grounded theory research: procedures, canons, and evaluative criteria. Qual Sociol. 1990;13(1):3-21.

34. Qidwai W, Ali S, Ayub S, Ayub S. Healing during physician-patient consultation. J Coll Physicians Surg Pak. 2005;15(11):689-692.

35. Wendler MC. Understanding healing: A conceptual analysis. J Adv Nurs. 1996;24(4):836-842.

36. Cowling WR. Healing as appreciating wholeness. ANS Adv Nurs Sci. 2000;22(3):16-32.
37. Thornton L. The model of whole-person caring: creating and sustaining a healing environment. Holist Nurs Pract. 2005;19(3):106-115.

38. Stewart M, Brown JB, Donner A, et al. The impact of patient-centered care on outcomes. J Fam Pract. 2000;49(9):796-804.

39. Bolles S, Maley M. Designing relational models of collaborative integrative medicine that support healing processes. J Altern Complement Med. 2004;10(Suppl 1):S61-S69.

40. Peabody FW. The care of the patient. JAMA. 1927;88:877-882.

41. Frank A. The Wounded Storyteller: Body, Illness, and Ethics. Chicago, IL: The University of Chicago Press; 1995.

42. Suchman AL. Story, medicine, and healthcare. Adv Mind Body Med. 2000;16(3):193-8, 19-207.

43. Pennebaker JW. Telling stories: the health benefits of narrative. Lit Med. 2000;19(1):3-18.

44. van der Poel CJ. Suffering and healing: the process of growth. Hosp Prog. 1981;62(2):42-47.

45. Winter RO, Birnberg BA. Finding meaning in suffering and healing. Fam Med. 2006;38(9):623-625.

46. Morse J, Johnson JL. The Illness Experience. Dimensions of Suffering Newbury Park, CA: SAGE Publications; 1991.

47. Schweitzer M, Gilpin L, Frampton S. Healing spaces: elements of environmental design that make an impact on health. J Altern Complement Med. 2004;10(Suppl 1):S71-S83.

48. Stanwick S, Farrow TS. Healing and the healthcare village: beyond the mega-hospital to a new model of health design. Hosp Q. 2003;6(4):66-72, 4

49. Rakel D, Jonas WB. Creating optimal healing environments. In: Rakel D, ed. Integrative Medicine. 2nd ed. Philadelphia, PA: Saunders; 2007:15-22

50. Koenig H. Spirituality in Patient Care: Why, How, When, and What Philadelphia, PA: Templeton Foundation Press; 2002.

51. Chez RA, Jonas WB. Spiritual Transformation and Health through the LifeCycle. In: Chez RA, Jonas WB, eds. Spiritual Transformation and Health through the LifeCycle. Radnor, PA; 2003.

52. Lind BK, Lafferty WE, Grembowski DE, Diehr PK. Complementary and alternative provider use by insured patients with diabetes in Washington State. J Altern Complement Med. 2006;12(1):71-77.

53. Jaen CR, Stange KC, Nutting PA. Competing demands of primary care: a model for the delivery of clinical preventive services. J Fam Pract. 1994;38(2):166-171.

54. Miller WL, Crabtree BF, Duffy MB, Epstein RM, Stange KC. Research guidelines for assessing the impact of healing relationships in clinical medicine. Altern Ther Health Med. 2003;9(3)(Suppl):A80-A95.

55. Chez RA, Jonas WB. Challenges and opportunities in achieving healing. J Altern Complement Med. 2005;11(Suppl 1):S3-S6.

56. Ludmerer KM. Learning to Heal. New York, NY: Basic Books; 1985

57. Remen RN. Recapturing the soul of medicine: physicians need to reclaim meaning in their working lives. West J Med. 2001;174(1):4-5.

58. Cherkin D, Sherman KJ, Mauksch LB, et al. The optimizing healing in primary care project. In: Building a National Research Model: The Future of HMO-Based Research. 2007 March 19-21; Portland, OR: HMO Research Network; 2007. 